\title{
ARTICLE
}

\section{Diffusion and sorption behavior of HTO, Cs, I and U in mortar}

\author{
Yosuke Akagi $^{\mathrm{a}^{*}}$, Hiroyasu Kato ${ }^{\mathrm{a}}$, Yukio Tachi ${ }^{\mathrm{b}}$ and Hiroyuki Sakamoto ${ }^{\mathrm{c}}$ \\ ${ }^{a}$ Mitsubishi Materials Corporation, 1002-14 Mukohyama, Naka-shi, Ibaraki-ken, 311-0102, Japan; ${ }^{b} J a p a n$ Atomic Energy Agency, \\ 4-33 Muramatsu, Tokai-mura, Naka-gun, Ibaraki-ken, 319-1194, Japan; ${ }^{c}$ Taiheiyo Consultant Corporation, 2-27-8 Higashi \\ Nihonbashi, Chuo-ku, Tokyo 103-0004, Japan
}

\begin{abstract}
Due to the accident of Fukushima Daiichi Nuclear Power Plant (NPP), a large amount of contaminated water has been generated in such as the reactor building. Concrete materials of the building have been in contact with contaminated water for a long time, therefore radionuclides in contaminated water may be penetrating into these concrete materials. For developing the plans of decommissioning of NPP and waste management including decontamination and disposal, it is important to estimate radionuclides inventory and concentration distribution in the concrete materials. For this purpose, the present study focuses on understanding the sorption and diffusion behavior and related mechanisms in the ordinary Portland cement (OPC) mortar. Effective diffusion coefficients $\left(\mathrm{D}_{\mathrm{e}}\right)$ and sorption distribution coefficients $\left(\mathrm{K}_{\mathrm{d}}\right)$ in OPC mortar for HTO, Cs, I and $U$ as key radionuclides were measured by the through-diffusion and batch sorption experiments. As a result, $\mathrm{D}_{\mathrm{e}}$ values of tracers derived were in the sequence of $\mathrm{HTO} \approx \mathrm{I}>\mathrm{Cs}>\mathrm{U}$, implying that cation exclusion effects may be important mechanisms in OPC mortar. $K_{d}$ values derived from diffusion and sorption experiments were consistently in the sequence of $\mathrm{U}>\mathrm{Cs}>\mathrm{I}$, however, the near-surface disturbance in diffusion samples and crushed effect in batch sorption samples must be considered for $\mathrm{K}_{\mathrm{d}}$ evaluation for high-sorbing radionuclides such as $\mathrm{U}$.
\end{abstract}

\section{Keywords: Fukushima Daiichi nuclear power plant; contaminated concrete; uranium; cesium; diffusion; sorption}

\section{Introduction}

Due to the accident of Fukushima Daiichi (1F) Nuclear Power Plant (NPP), a large amount of concrete wastes like rubble contaminated by radioactive cesium has been generated. Moreover, it is assumed that a large amount of concrete waste will be generated by the cleanup and decommissioning activities [1]. Especially, concrete materials of the reactor building have been in contact with contaminated water for a long time. Therefore, it is considered that radionuclides ( $R N)$ in contaminated water may be penetrating into these concretes. For consideration of decommissioning and disposal, it is important to estimate RNs inventory and concentration distribution in the concrete materials. However, a lot of diffusion data of water in concrete has been acquired using HTO [2,3], but the diffusion data of RNs such as Cs and $U$ in concrete is very limited [4]. In this study, sorption distribution coefficients $\left(\mathrm{K}_{\mathrm{d}}\right)$ and effective diffusion coefficients $\left(\mathrm{D}_{\mathrm{e}}\right)$ of key RNs, HTO, $\mathrm{Cs}, \mathrm{I}$ and $\mathrm{U}$, in OPC (ordinary Portland cement) mortar were measured by the through-diffusion and batch sorption experiments. HTO was used for understanding the fundamental diffusion characteristics. Cs and I were

*Corresponding author. Email: akagiy@mmc.co.jp used as typical cation and anion, respectively. U(VI) was used as a representative of more complex actinides. Sorption and diffusion behavior and related mechanisms in OPC mortar were evaluated to predict the RNs inventory and distribution in the concrete materials.

\section{Experimental}

\subsection{Mortar samples}

OPC mortar samples used in this study were selected based on the following reasons. The OPC was selected as a standard cement and due to the existence of related data. Migration of RNs in concrete is affected by the properties of aggregate in addition to the properties of cement paste. Especially, the sorption properties for aggregates strongly influence the time until the RNs breakthrough by diffusion in concrete, and it was estimated that the breakthrough could not be obtained for high-sorbing tracers. Therefore, in this study, concrete was produced using limestone as aggregate having weak sorption for RNs. In addition, if the thickness of the sample was cut thicker than the coarse aggregate's size, the diffusion experiments would need a very long time to obtain the nuclide break through, so mortar samples using diffusion experiments were made 
without coarse aggregates. The mortar sample was prepared by mixing with a predetermined formulation including coarse aggregate and then removing the coarse aggregate and retaining the fine aggregate by a wet screening method. The mortar samples were cured for 4 weeks, the porosity and density was measured by mercury intrusion porosimetry, and the specific surface area was measured by BET adsorption method (Table 1).

Table 1. Composition and characteristic of the OPC mortar sample

\begin{tabular}{|c|c|c|c|}
\hline \multicolumn{4}{|c|}{ Amount $\left(\mathrm{kg} \mathrm{m}^{-3}\right)$} \\
\hline Water & Cement & $\begin{array}{c}\text { Fine } \\
\text { aggregate }\end{array}$ & $\begin{array}{c}\text { Coarse } \\
\text { aggregate }\end{array}$ \\
\hline 175 & 318 & 882 & 943 \\
\hline \hline \multicolumn{4}{|c|}{ Measured characteristic } \\
\hline Porosity & Bulk density & Surface area (BET) \\
\hline $14.2 \%$ & $2.32 \mathrm{Mg} \mathrm{m}^{-3}$ & $12.5 \mathrm{~m}^{2} \mathrm{~g}^{-1}$ \\
\hline
\end{tabular}

\subsection{Diffusion experiments}

Diffusion experiments were conducted at room temperature and in an argon atmosphere in order to avoid the dissolution of carbon dioxide in solution and the precipitation of $\mathrm{CaCO}_{3}$ at surface of OPC mortar. OPC mortars were cut into disk shapes $(50 \mathrm{~mm}$ in diameter and $5 \mathrm{~mm}$ in thickness) were set to a through-diffusion type cell (Figure 1). Two reservoirs (inlet and outlet) of the diffusion cell were filled by test solution, and the mortar samples were pre-saturated by evacuation. The test solution used is deionized water equilibrated with mortar, and its $\mathrm{pH}$ was expected to be kept at 12.5 by dissolution of $\mathrm{Ca}(\mathrm{OH})_{2}$ in the mortar [5]. The initial tracer concentrations of HTO, Cs, I and $\mathrm{U}(\mathrm{VI})$ were $13.9 \mathrm{kBq} \mathrm{mL}^{-1}, 8.1 \times 10^{-8} \mathrm{~mol} \mathrm{~mL}^{-1}, 9.8 \mathrm{x}$ $10^{-8} \mathrm{~mol} \mathrm{~mL}^{-1}$ and $2.5 \times 10^{-8} \mathrm{~mol} \mathrm{~mL}^{-1}$. All diffusion experiments were conducted in duplicate under the same conditions. Tracer concentrations in both reservoirs were continuously monitored until the concentration increase in the outlet reservoir approached near linear. These tracer concentrations were measured by using Liquid Scintillation Counter (LSC: Perkin Elmer) for HTO and Inductively Coupled Plasma Mass Spectrometer (ICP-MS: Agillent) for Cs, I and U. At the end of the

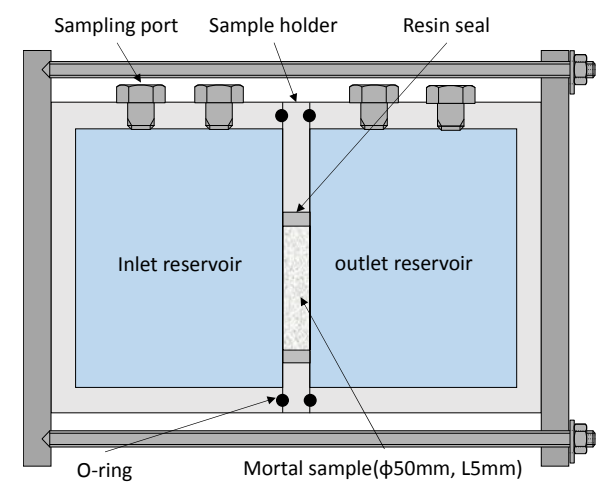

Figure 1. Through diffusion cell. diffusion test, the diffusion cells for Cs and U(VI) were disassembled and the mortar samples were drilled, and the obtained fine powders were leached with $\mathrm{HNO}_{3}$, and the concentrations of tracer in the leachate were measured by ICP-MS.

\subsection{Batch sorption experiments}

Batch sorption experiments for Cs, I and U(VI) were conducted at room temperature and in an argon atmosphere in the same way as the diffusion experiments. OPC mortars were crushed to powder $(<0.25 \mathrm{~mm})$ and were immersed in polypropylene bottles with test solution equilibrated with mortar at a liquid to solid ratio of $10 \mathrm{~mL} \mathrm{~g}^{-1}$ ( $3 \mathrm{~g}$ solid in $30 \mathrm{~mL}$ solution). The initial tracer concentrations of Cs, I and U(VI) were set equal to the diffusion experiments. The batch experiments were carried out for 28 days and the sorption was confirmed to have reached equilibrium. The solution containing these tracers were passed through a $0.45 \mu \mathrm{m}$ membrane filter (PTFE; Advantec ) and the concentrations of tracer were measured by ICP-MS. All sorption experiments were conducted in triplicate, and a blank test without OPC mortar was also conducted.

\section{Results and discussion}

\subsection{Diffusion experiments}

The diffusion and sorption characteristics of OPC mortars were calculated from the results of the through diffusion experiments using Fick's second law. A rigorous analytical solution that considers a decrease concentration in inlet reservoir and an increase concentration in outlet reservoir can be described as follows [6];

$$
\begin{gathered}
C(x, t)=\frac{C_{1}}{\delta+\gamma+1}- \\
2 C_{1} \sum_{m=0}^{\infty} \frac{\exp \left(-\frac{D_{e} \cdot \varphi_{m}{ }^{2}}{\alpha \cdot L^{2}} \cdot t\right) \cdot\left[\delta \cdot \cos \left(\varphi_{m} \cdot \frac{L-x}{L}\right)-\gamma \cdot \varphi_{m} \cdot \sin \left(\varphi_{m} \cdot \frac{L-x}{L}\right)\right]}{\left[\gamma \cdot \varphi_{m}^{2}-\delta(\delta+\gamma+1)\right] \cdot \cos \left(\varphi_{m}\right)+(\delta \gamma+\delta+2 \gamma) \cdot \varphi_{m} \cdot \sin \left(\varphi_{m}\right)}
\end{gathered}
$$

where $\mathrm{C}_{1}$ is the initial concentration of inlet reservoir $\left(\mathrm{Bq} \mathrm{mL} L^{-1}\right.$ or mol mL $\left.\mathrm{m}^{-1}\right), \mathrm{L}$ is the thickness of a sample $(\mathrm{m}), \alpha$ is the capacity factor $(-), \mathrm{x}$ is the distance $(\mathrm{m}), \mathrm{t}$ is the time (s), $\delta=(\alpha \cdot \mathrm{A} \cdot \mathrm{L}) / \mathrm{V}_{\text {in }}, \gamma=\mathrm{V}_{\text {out }} / \mathrm{V}_{\text {in }}$ and $\varphi_{\mathrm{m}}$ is the root of the following equation:

$$
\tan (\varphi)=\frac{\delta \cdot(\gamma+1) \cdot \varphi}{\gamma \cdot \varphi^{2}-\delta^{2}}
$$

where $\mathrm{A}$ is the cross-sectional area of a sample $\left(\mathrm{m}^{2}\right)$ and $\mathrm{V}_{\text {in }}$ and $\mathrm{V}_{\text {out }}$ are the volumes of the inlet and outlet reservoirs $\left(\mathrm{m}^{3}\right)$.

Breakthrough curves in the outlet reservoir for HTO, Cs and I were obtained (Figure 2). $\mathrm{D}_{\mathrm{e}}$ of HTO, $\mathrm{D}_{\mathrm{e}}$ and $\mathrm{K}_{\mathrm{d}}$ values of $\mathrm{Cs}$ and I were calculated by fitting to change for tracer's concentration both of inlet and outlet reservoirs using a rigorous analytical solution. Calculated $D_{\mathrm{e}}$ values of HTO were $4.7 \sim 5.1 \times 10^{-12} \mathrm{~m}^{2}$ $\mathrm{s}^{-1}$ and $\mathrm{D}_{\mathrm{e}}$ values of Cs were $0.69 \sim 1.1 \times 10^{-12} \mathrm{~m}^{2} \mathrm{~s}^{-1}$ and 
$D_{e}$ values of I were $3.5 \sim 6.4 \times 10^{-12} \mathrm{~m}^{2} \mathrm{~s}^{-1}$. The $\mathrm{D}_{\mathrm{e}}$ values of HTO are exactly consistent with an empirical relationship between porosity and $\mathrm{D}_{\mathrm{e}}$ of OPC [2]. $\mathrm{D}_{\mathrm{e}}$ values of I were almost identical as HTO. $\mathrm{D}_{\mathrm{e}}$ value of Cs was slightly lower than $\mathrm{D}_{\mathrm{e}}$ of HTO and I. It suggests that the diffusion of cation in the pore of mortar and the positive charge on the surface of cement hydrate [7] cause an electrostatic interaction. Although there is some scatter in the data during early stages, the concentration of $I$ in the inlet reservoir indicated a decrease due to the sorption onto the cement hydrate.

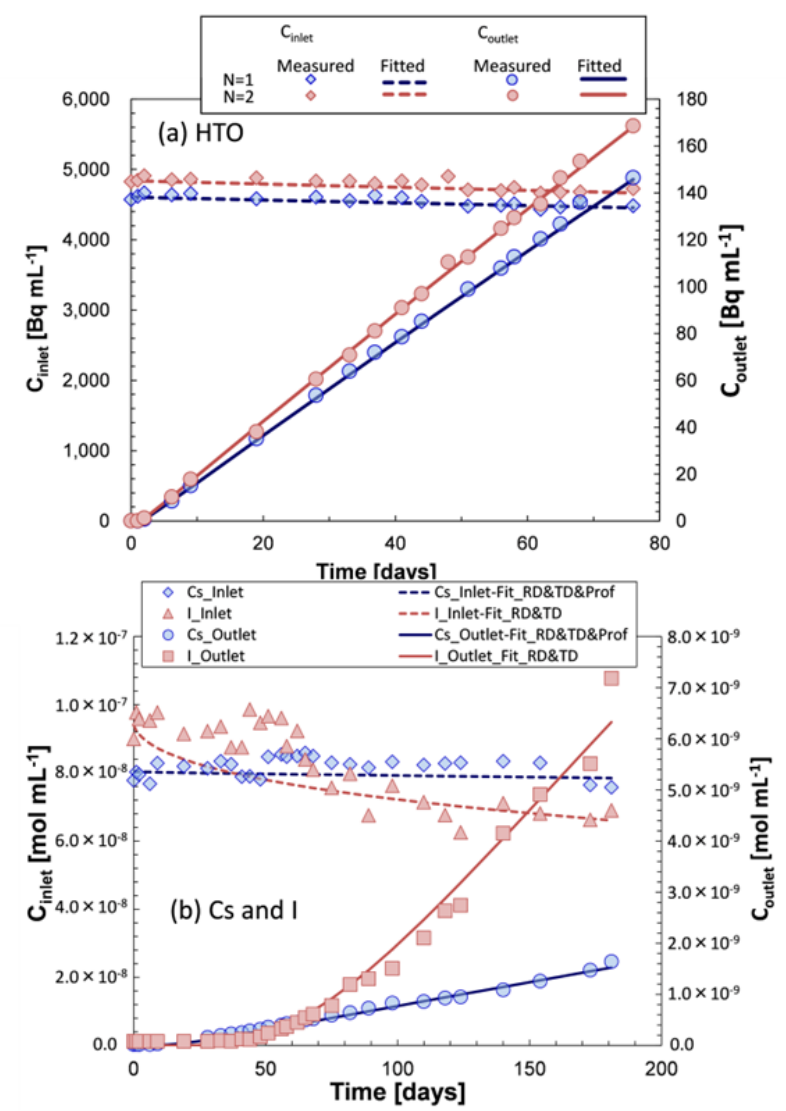

Figure 2. Concentration of HTO, Cs, and I tracers.

In the U(VI) case, the breakthrough curves could not be obtained, then depth profiles were analyzed. The depth profiles of Cs were also measured in the same way as $\mathrm{U}(\mathrm{VI})$. The measured depth profile is shown in Figure 3. Typical dual profiles were observed for $U$ and Cs. One of them has a high concentration gradient near the surface on the inlet reservoir (near profile), the other one has a lower concentration gradient extending into the sample (far profile). These are similar to existing observations for Cs diffusion in mortar [8] and granitic rock [9]. These suggest that the diffusion behavior is different between the near-surface and the deeper parts.

The profile of U(VI) in the sample showed more than $90 \%$ of $U$ remained in the area from the surface to the depth of $1 \mathrm{~mm}$. Concentration of U(VI) at near the surface decreased more than one order of magnitude. These might be strong sorption at the surface of the mortar sample. Concentration of Cs near the surface decreased to about half of the level of the surface. This might be weak sorption compared with U(VI).

$\mathrm{D}_{\mathrm{e}}$ values of these RNs shown in Figure 4 were in the sequence of $\mathrm{HTO} \approx \mathrm{I}>\mathrm{Cs}>\mathrm{U} . \mathrm{D}_{\mathrm{e}}$ value of $\mathrm{U}(\mathrm{VI})$ was estimated as about $5 \times 10^{-13} \mathrm{~m}^{2} \mathrm{~s}^{-1}$ from the far profile. The $D_{e}$ values of $U(V I)$ was one order lower than $D_{e}$ of HTO and I, and slightly lower than $\mathrm{D}_{\mathrm{e}}$ of Cs. Regarding $D_{e}$ values of $C s$, the $D_{e}$ calculated from the breakthrough curve and $D_{e}$ obtained from the far profile were almost identical. Likewise for $\mathrm{U}(\mathrm{VI})$, the $\mathrm{D}_{\mathrm{e}}$ value calculated from the breakthrough curve is expected to be close to the $D_{e}$ value calculated from the far profile.
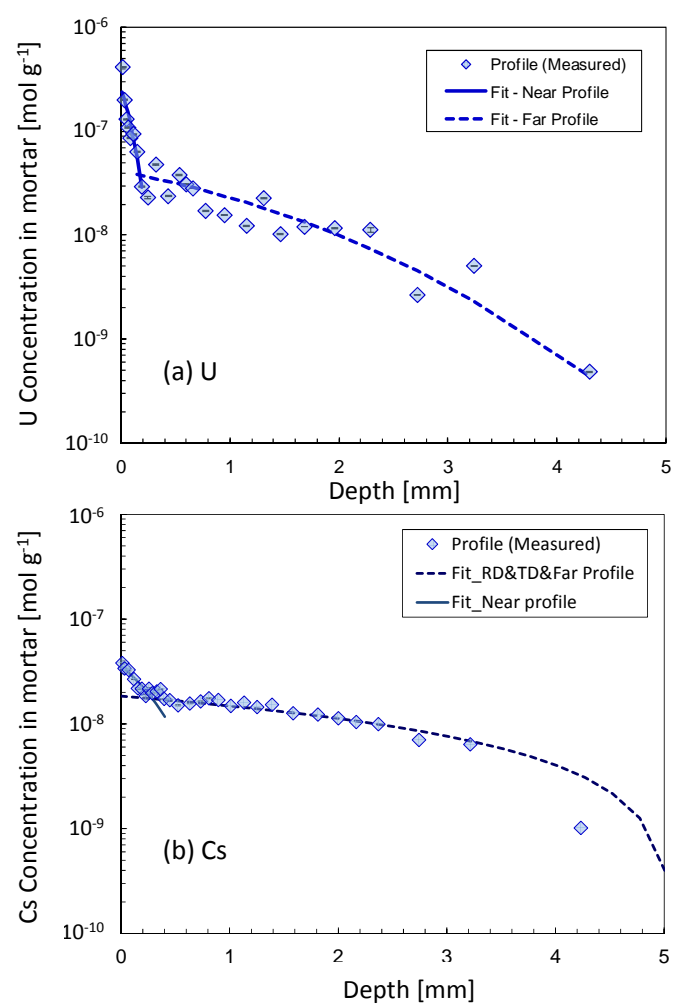

Figure 3. Depth profiles of Cs and U(VI) in OPC mortar.

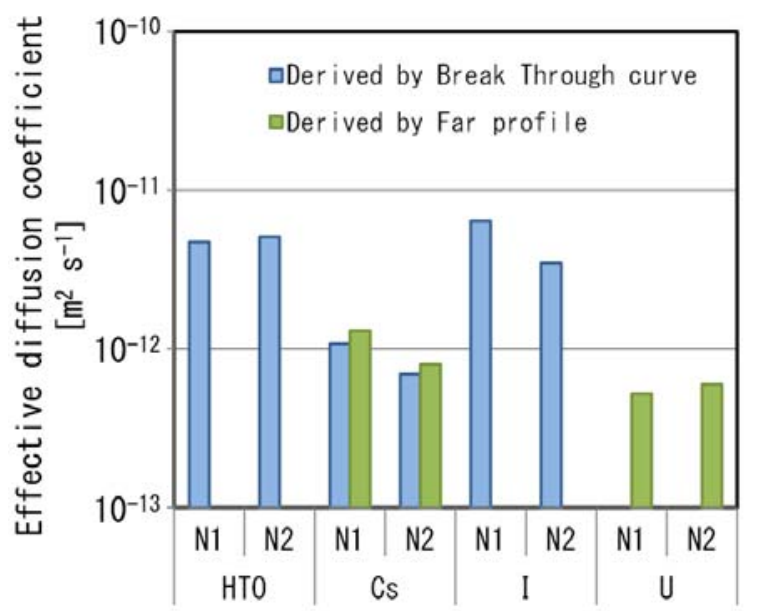

Figure 4. The $\mathrm{D}_{\mathrm{e}}$ of HTO, Cs, I, and U(VI) in OPC mortar, obtained from through diffusion experiments. 


\subsection{Batch sorption experiments}

The $\mathrm{K}_{\mathrm{d}}$ values were determined from the following equation

$$
K_{d}=\frac{\left(C_{i n i}-C_{e q}\right)}{C_{e q}} \times \frac{V}{W}
$$

where $\mathrm{C}_{\mathrm{ini}}$ and $\mathrm{C}_{\mathrm{eq}}$ are the equilibrium concentrations of tracers in the test batch and blank batch $\left(\mathrm{mol} \mathrm{m}^{-3}\right)$, respectively. $\mathrm{V}$ is the volume of liquid phase $\left(\mathrm{m}^{3}\right)$, and $\mathrm{W}$ is the mass of solid phase $(\mathrm{kg})$. The $\mathrm{K}_{\mathrm{d}}$ values are shown in Figure 5, compared with the $\mathrm{K}_{\mathrm{d}}$ values calculated from the results of diffusion experiments. The $\mathrm{K}_{\mathrm{d}}$ values of Cs, I and $\mathrm{U}$ were in the sequence of $\mathrm{U}>\mathrm{I}>$ Cs in both of the batch sorption experiments and fitting to diffusion experiments. This sequence is similar with a previous report [7]. The $\mathrm{K}_{d}$ values of $\mathrm{U}(\mathrm{VI})$ had a noticeable difference between batch sorption and diffusion experiments. $K_{d}$ values derived from batch tests $\left(\mathrm{Kd}=7.8 \mathrm{~kg} \mathrm{~m}^{-3}\right)$ were higher by more than two orders of magnitude than the diffusion-derived $\mathrm{K}_{\mathrm{d}}$ values $\left(\mathrm{K}_{\mathrm{d}}=0.011 \mathrm{~kg} \mathrm{~m}^{-3}\right)$. The $\mathrm{K}_{\mathrm{d}}$ value of Cs is in the sequence of the far profile $<$ near profile $<$ batch sorption. This trend was also observed for $\mathrm{U}(\mathrm{VI})$, however, in the U(VI) case, the difference between batch sorption and the diffusion experiment is significantly large. From this, it is thought that U(VI) sorption is strongly affected by the disturbances at near-surface of diffusion samples and crushed samples.

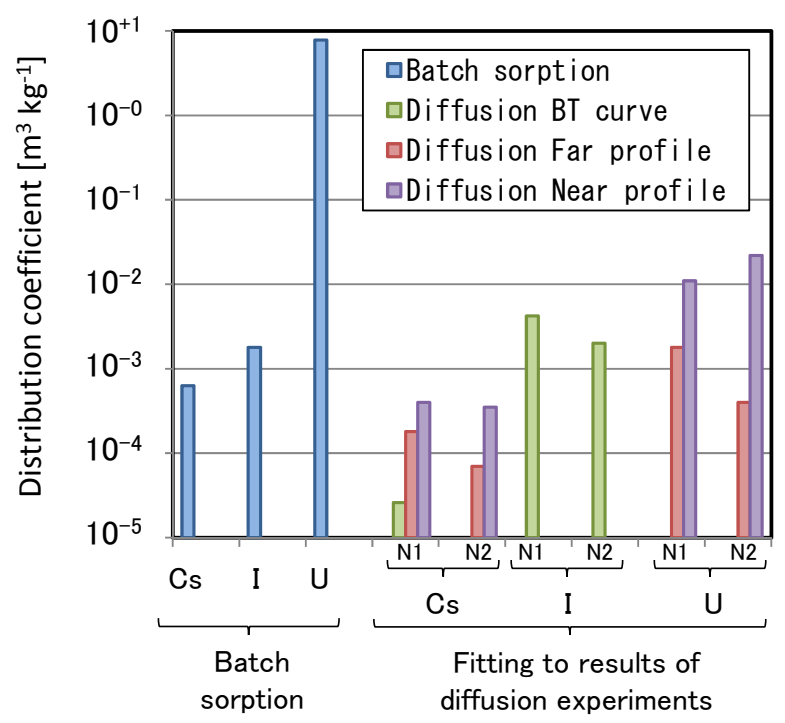

Figure 5. The distribution coefficients of Cs, I, and U(VI), obtained from batch sorption and diffusion experiments.

\section{Conclusions}

The $\mathrm{D}_{\mathrm{e}}$ and $\mathrm{K}_{\mathrm{d}}$ value in the OPC mortar for HTO, Cs, $\mathrm{I}$ and $\mathrm{U}$ were measured by the through-diffusion and batch sorption experiments. As a result, the influence of charge of diffusion species on diffusion characteristics was confirmed in cement mortar which is complex of plural minerals and hydrates. Trends of the $\mathrm{D}_{\mathrm{e}}$ value were in the sequence of $\mathrm{HTO} \approx \mathrm{I}>\mathrm{Cs}$, it might be suggested that the positive charge on the surface of cement hydrate cation effected for diffusion of Cs. And the tendency of $\mathrm{K}_{\mathrm{d}}$ values were consistent with the batch sorption and diffusion experiment then the batch experiments is also effective, but depending on the high-sorbing RNs such as $\mathrm{U}(\mathrm{VI})$, it is necessary attention to inconsistency of the batch sorption and diffusion due to near-surface disturbance in diffusion samples and crushed effect in batch sorption samples. The sorption and diffusion trends and their mechanisms observed here are important to evaluate RNs inventory and concentration distribution in the concrete materials, and should be reflected for developing the plans of decommissioning NPPs and waste disposal.

\section{References}

[1] Nuclear Emergency Response Headquarters Government and TEPCO's Mid-to-Long Term Countermeasure Meeting, "Mid-and-long Term Roadmap towards the Decommissioning of Fukushima Daiichi Nuclear Power Station Units 1-4, TEPCO”, (2011).

[2] Japan Nuclear Cycle Development Institute, RAdio-nuclides Migration DAtasets (RAMDA) on cement, bentonite and rock for the performance assessment of TRU waste repository in Japan, JNC TN8400 2005-027, (2005).

[3] S. Numata, H. Amano and K. Minami, Diffusion of tritiated water in cement materials, Journal of Nuclear Materials 171 (1990), pp. 373-380.

[4] T. Nishi, O. Kuriyama, M. Matsuda, K. Chino and M. Kikuchi, Porosity and ion diffusivity of latex-modified cement, Mat. Res. Soc. Symp. Proc. 176 (1990), pp.109-114.

[5] A. Atkinson, J.A. Hearne and C.F. Knights, Aqueous chemistry and thermodynamic modelling of $\mathrm{CaO}-\mathrm{SiO}_{2}-\mathrm{H}_{2} \mathrm{O}$ gels, AERE $\mathrm{R} 12543$ (1987).

[6] M. Zhang, M. Takeda and H. Nakajima, Determining the transport properties of rock specimens using an improved Laboratory through-diffusion technique, Mat. Res. Soc. Symp. Proc. 932 (2006).

[7] M. Ochs, D. Mallants and L. Wang, Radionuclide and metal sorption on cement and concrete, Topics in Safety, Risk, Reliability and Quality 9 (2016).

[8] K. Idemitsu, K. Kuwata, H. Furuya, Y. Inagaki, T. Arima, Diffusion paths of cesium in watersaturated mortar, Nuclear Technology 118 (2008), pp. 747-752.

[9] Y. Tachi, T. Ebina, C. Takeda, T. Saito, H. Takahashi, Y. Ohuchi and A.J. Martin, Matrix diffusion and sorption of $\mathrm{Cs}^{+}, \mathrm{Na}^{+}, \mathrm{I}^{-}$and HTO in granodiorite: Laboratory-scale results and their extrapolation to the in situ condition, Journal of Contaminant Hydrology 179 (2015), pp. 10-24. 